\title{
Multifactor consumption based asset pricing models using the US stock market as a reference: evidence from a panel of developed economies.
}

\author{
John Hunter* \\ Department of Economics and Finance, School of Social Science \\ Brunel University, Uxbridge, Middlesex UB8 3PH, UK \\ Feng $\mathrm{Wu}$ \\ Banco Santander, London
}

\begin{abstract}
This article considers a panel framework to test consumption based asset pricing models driven by a US stock market references for a number of developed economies. Specifically, we focus on a linearized form of what might be seen as a consumption-based capital asset pricing model in a pooled cross section panel model with two-way error components. The empirical findings of this multifactor model using a range of specifications indicate that there is significant unobserved heterogeneity captured by cross-country fixed effects when consumption growth is treated as a common factor. However, the cross-sectional impact of home consumption growth varies dramatically over the countries, where unobserved heterogeneity in the rate of risk aversion can also be addressed by random effects. Keywords: Consumption based asset pricing model, Generated Regressor, Multi-factor Model, Panel Estimation, Random Effects JEL Classification: C52, E44, G12
\end{abstract}




\section{Introduction}

Empirical studies have already shown that the conditional covariances between the Intertemporal Marginal Rate of Substitution (IMRS) in consumption and returns cannot satisfy the equilibrium restrictions imposed by the representative agent Consumption-based CAPM (C-CAPM) for different countries (Kocherlakota, 1996). This has led to a great research interest in C-CAPM taking account of heterogeneity and idiosyncratic risk (Lund and Engsted, 1996). The issue of heterogeneous risk in asset pricing was first addressed by Miller (1977), and then revisited by other authors, i.e., Constantinides and Duffie (1996), Jacobs and Wang (2004). It has been concluded that heterogeneous risk has a better chance of explaining the data than standard representative-agent C-CAPM models (Jacobs and Wang, 2004).

Recently in the context of aggregate time serious Gregoriou et al (2009) using monthly data for the US and Hunter and Wu (2009) using similar data for the UK find via some form of augmentation that consumption based models can be seen as one of the drivers of the riskier component of asset valuation. Gregoriou et al (2009) develop a Vector Autoregressive (VAR) model of US asset prices where excess returns are simultaneously explained by consumption growth, real money growth and inflation. The model is conditioned on a single exogenous variable income growth and controlled where appropriate for Autoregressive Conditional Heteroscedasticity $(\mathrm{ARCH})$ and the major financial shocks to the economy. Hunter and Wu (2009) address the importance for the UK market of simultaneous heterogeneity proxied by a US stock market reference. The analysis in Hunter and $\mathrm{Wu}$ (2009) considered a limited information framework and found that UK excess returns were explained by two primary factors consumption growth and US excess returns. The second factor in the case of the UK study appears to capture the volatility in the return series and once this feature of the data is captured then consumption captures the fundamental growth factor driving the UK stock market.

In this article, a similar approach is applied to data on excess stock returns for a number of developed economies to see whether the primary multifactor nature of the explanation of an economies assets in Hunter and $\mathrm{Wu}(2009)$ extends beyond the Anglo Saxon financial model. US excess returns are used in a number of different specifications of a two-way error component panel model to study whether there is any measurable heterogeneity or idiosyncratic risk related to excess returns and consumption growth either across countries or over time.

The rest of this article is organized as follows. A brief review of the literature is given in section 2. Section 3 and 4 describe the data properties and the methodology applied in this paper, respectively. Section 5 reports the empirical results. Finally, section 6 contains some concluding remarks.

\section{The Consumption CAPM Literature}

In the last three decades, the poor performance of the standard Consumptionbased CAPM(C-CAPM) has been well examined in a time series context. Within the C-CAPM framework, the performance of these models have improved by applying different pricing kernels to incorporate different types of heterogeneity 
that have been neglected by the standard C-CAPM. In the context of preferences related to the standard power utility function see Abel (1990), Constantinides (1990), Ferguson and Constantinides (1991), Heaton (1993), and Epstein and Zin (1991). While Constantinides and Duffie (1996), Heaton and Lucas (1997), Mankiw (1986), and Storesletten, Telmer, and Yaron (1999) consider complete asset market systems. Mankiw and Zeldes (1991) consider the problem in terms of limited market participation, and Fisher (1994), He and Modest (1995), Margueering and Verbeek (1999), and Gregoriou and Ioannidis (2006) find evidence for market frictions.

Constantinides and Duffie (1996) provide a theoretical framework for assessing the effects of market incompleteness on financial market equilibrium, under which the conditional covariances between returns and the Intertemporal Marginal Rate of Substitution (IMRS) in consumption mean that it is not possible to attain a full equilibrium. They derive a pricing kernel for an economy where individuals with isoelastic preferences are subject to idiosyncratic income shocks. The pricing kernel depends on aggregate consumption growth as well as the cross-sectional variance of per-capita log consumption growth. If this variance is negatively correlated with equity returns, the heterogeneous economy has a higher equity premium and lower risk-free rate than the standard model predicts. Thus, there is the potential for this type of model to resolve the asset-pricing puzzles.

Following the theoretical intuition of Constantinides and Duffie, several papers have investigated empirically the role of heterogeneity induced by market incompleteness. However, the results are mixed. For example, Jacobs (1999) uses the US Panel Study of Income Dynamics (PSID) data on food consumption to estimate individual Euler equations for the 1974-1987 period, and find that joint tests on the risky and riskless asset strongly reject the model. While Cogley (2002) generalizes the pricing kernel of Constantinides and Duffie (1996) to test the approach using data from the US Consumption Expenditure Survey (CEX) for the 1980-1994 period. However, these findings indicate that measures of the cross-sectional dispersion of log consumption growth are only weakly correlated with stock returns, and that pricing kernels depending on these cross-sectional measures generate unrealistically small equity premia for preference specifications with low degrees of risk aversion. With the same CEX data set, Brav, Constantinides, and Geczy (2002) test a pricing kernel obtained from the aggregation of the IMRS models. By permitting heterogeneity, this kernel can help reconcile the problems that arise with consumption-based models as their models suggest coefficients of risk aversion between 3 and 4 that are more consistent with what might be anticipated from theory.

More recently, Jacobs and Wang (2004), Semenov (2003), and Balduzzi and Yao (2007) also investigate idiosyncratic consumption risk within the crosssectional C-CAPM. Jacobs and Wang (2004) compare the traditional CAPM with a two-factor C-CAPM that is related to cross-sectional consumption variation that captures the possibility of idiosyncratic risk. They demonstrate that consumption risk described by cross-sectional consumption variation can contribute to the cross-sectional average returns of stocks, and the performance is similar to the consumption surplus ratio of the conditional C-CAPM of Campbell and Cochrane (2000). Also, Semenov (2003) develops an appropriate equilibrium factor model using the cross-moments of asset returns and the crosssectional moments of individual consumption, aggregated by a dummy variable 
for risk signs. He finds that the model explains the observed equity premium with realistic values of risk aversion. Instead of using the cross-sectional variance of log consumption growth Constantinides and Duffie (1996), and Balduzzi and Yao (2007) employ the growth of the cross-sectional variance of log consumption and develop a new heterogeneous-agent pricing kernel based upon the cross-sectional aggregation of marginal utilities. With reasonable coefficients of relative risk aversion, their model can explain the US risk premium by the consumption of asset holders.

It can be seen from the above discussion that although the debate over the specific pattern of heterogeneity in either consumption or returns has not reached a conclusion, the approach has a capacity to solve both of the puzzles. Hunter and $\mathrm{Wu}(2009)$ suggest a C-CAPM framework that includes a US wealth reference as an alternative to the home consumption habit to reconcile different volatilities between returns and consumption growth data for the UK. The introduction of this new risk factor can appropriately mimic the cross-country heterogeneity in both returns and consumption when they exist. They find that for the UK model, the US stock market is the primary source of the low correlation between UK returns and consumption growth rates, since effects resulting from the external market are much stronger than the UK consumption habit. Therefore, the integration of stock markets can at least alter the investors' expectations of risk returns and account for the disequilibrium of the conditional covariances between risk premia and consumption for the UK C-CAPM model. This would seem reasonable for a market that for more than a century has had a regard for the influence of global returns and where more recently stocks have been cross listed and since financial liberalization that followed in 1986 significant waves of cross Atlantic merger activity have taken place.

However, it can be argued whether imperfect asset diversification across international securities markets is also the primary source of low cross-country correlation of consumption growth rates and whether high cross-country correlation of excess returns is supported by evidence from other countries, or unique only to the UK. Today, the international integration of financial markets is a central characteristic of the globalization process and a potential force for driving changes in the institutions of corporate governance. For example, cross-border portfolio investment funds have expanded dramatically. Also, the number of foreign companies listed on the two major US stock markets has increased significantly, though there is still evidence for a home bias in investors' portfolio decisions (Opoku, 2007). These trends indicate a convergence in the institutions of corporate governance at national levels to the US system and the standards of US institutional investors. The ultimate impact will be the worldwide dominance of the US markets with respect to monetary policy and corporate governance and this does not seem to have been thus far changed by the credit crunch of the later part of the last decade. In fact the integratedness of markets seems more important than ever.

In this paper we argue that it is natural to consider a panel as a more appropriate econometric approach to analyze the C-CAPM when non-US stock markets are converging to the US market, and it is also natural to use panel techniques to handle heterogeneity and measurement errors. ${ }^{1}$ Panel data techniques

\footnotetext{
${ }^{1}$ Panel data techniques provide a coherent methodology to flexibly deal with both the homogeneous and heterogeneous parameters of the country models. For more general issues,
} 
provide a coherent methodology to flexibly deal with both the homogeneous and heterogeneous parameters of the country models, and after correcting for individual effects, any further heterogeneity at the level of the individual country would suggest that important predictive variables have been omitted from the models. On the other hand, measurement errors can lead to under-identification of an econometric model. However, the availability of multiple observations for a given individual or at a given time may allow one to estimate different model specifications, and thus observe alternative parameters of these models. The problem of measurement error in variables can be particularly important and relevant for the two-step regressions estimated here. Although IV and GMM estimation have been deployed to minimize the extent to which it affects the time series analysis (Hunter and $\mathrm{Wu}, 2009$ ), it is still worthwhile to investigate this problem further in a panel setting. A third issue is the effect of correlation and causation, both of which are of interest in statistical studies. In particular, correlation is very important for econometric studies. Panel data analysis permits us to extract from the data a range of different kinds of correlation at the level of individual country (autocorrelation), across individual countries (contemporaneous correlation) and across time.

A small number of panel data studies exist for the C-CAPM that consider country-specific effects while cross-country studies are more common in the literature (i.e. Lund and Engsted, 1996), where C-CAPM models have been estimated separately without considering cross-country correlation. The cross-sectional approach can limit the potential robustness and efficiency of the findings with respects to country specific effects and time related effects. There are only a few studies with panel data on returns and portfolio allocation, for example, the well known two dimensional panel - the 25 Fama-French portfolios, sorted with respect to five size and five book-to-market categories (Fama and French, 1996; Hodrick and Zhang, 2001; Campbell and Vuolteenaho, 2002). ${ }^{2}$

\section{Descriptive Statistics}

The historical quarterly panel data used cover nine typical developed stock markets, with data collected from DataStream. Specifically, the nine countries are Australia (AU), Germany (BD), Canada (CN), Denmark (DK), Spain (ES), France (FR), Italy (IT), Switzerland (SW) and the United Kingdom (UK). With the exception of Denmark, these are all important countries with regard stock market capitalization. ${ }^{3}$ The reason for including the Danish market is

\footnotetext{
see the survey (Hsiao, 2007)

${ }^{2}$ Dynamic Panel Data analysis (DPD) that derives from the work of Arrelano and Bond (1991) has to be discussed when panel data models are estimated by GMM. The general model that can be estimated with DPD is a single equation with individual and time specific effects, and an error term that should be serially uncorrelated to satisfy some set of common factor restrictions. However, DPD is not appropriate for the estimation of the current nine-country C-CAPM, since it is designed for cases where the cross section dimension is large and the time series dimension small. Moreover, DPD is indeed an autoregressive structure that includes AR terms as explanatory variables, which is not necessary for the C-CAPM definition when it is anticipated that the residuals ought not to be correlated.

${ }^{3}$ It should be noted that the second largest stock market - the Japanese stock market has been neglected due to the illiquidity problem. Also, as documented in the literature, the Japanese stock market in the previous 15 years is not as relevant to the world market as those of other mature stock markets. Thus, it is not considered here in panel models.
} 
that it retains its own currency and monetary policy, which is rare in Europe today, and thus can be expected to help show along with the UK, the extent to which heterogeneity exists. The consumption data $\left(C_{t}\right)$ are private consumption expenditures, seasonally adjusted and measured at constant prices. Due to data availability short-term interest rates $\left(r_{t}^{f}\right)$ of corresponding countries are chosen as 3-month rates of either Treasury/Government bills or as interbank rates. As far as the stock indices are concerned, recognized world indices are preferred due to their impact on the market, trading volumes and the corresponding derivatives linked to them. However, when we have too few observations, we use corresponding composite indices. Table 1 gives detailed information about the stock indices and interest rates selected.

The effect of the reunification of Germany at the end of 1990 should be noted as it might introduce a structural break by virtue of the economic change engendered and since the consumption data relate now to the former East and West Germany. However, it is felt this country cannot be excluded from the panel since it is so important, ${ }^{4}$ and thus the sample is limited to 1991:Q12004:Q4.

Table 1 Data Information on 9 Selected Countries

\begin{tabular}{c|ccc} 
Country & $\begin{array}{c}\text { Market }^{\text {Capitalisation }} \\
\text { * }\end{array}$ & $\begin{array}{c}\text { Source of interest } \\
\text { rates }\end{array}$ & Market index \\
\hline Australia & 776.2 & Interbank & ASX ALL ORDINARIES \\
Germany & 1194.5 & Interbank & DAX30 \\
Canada & 1177.5 & Interbank & TORONTO SE \\
Denmark & 155.2 & Interbank & COMPOSITE INDEX \\
Spain & 940.7 & Interbank & MADRID SE GENXRA20 \\
France & 1435.7 & Pibor & CAC40 \\
Italy & 789.6 & G-bill & MILAN MEX \\
Switzerland & 825.8 & Interbank & SWISS MARKET PRICE \\
United Kingdom & 2865.2 & T-bill & INDEX \\
& & & FTSE100
\end{tabular}

*:Data source is from World Bank annual report 2005 (in billions of

US dollars), where the US stock market is reported as $\$ 16323.5$.

It should be noted that $\hat{r}_{U S}^{e}{ }^{1}$ and $\hat{r}_{U S}^{e}{ }^{2}$ are fitted values recalculated from the US return equation developed in Gregoriou et al (2009) that are respectively with and without dummies. ${ }^{5}$ The reason that expectations on extreme observations have to be recalculated is because of the market timing which indicates that shocks are not predicted in advance. Apparently, it is not surprising as when compared with the actual values $r_{U S}^{e}, \hat{r}_{U S}^{e}{ }^{1}$ is smoother while $\hat{r}_{U S}^{e}{ }^{2}$ is even more stable, and the correlation coefficients of nine major stock indices related to $\hat{r}_{U S}^{e}{ }^{2}$ are on average less than half of those related to $r_{U S}^{e}$ and $\hat{r}_{U S}^{e}{ }^{1}$. Unpredictable outliers may induce powerful correlations, suggesting their exclusion when the analysis requires rational asset pricing. However, some persistent correlations do exist across individual stock markets as can be observed in Table 2 and Table 3 for excess returns and consumption growth, respectively.

\footnotetext{
${ }^{4}$ This can be seen by the central role of the Deutsch Market in the EMS and the decision to position the ECB in Frankfurt prior to the introduction of the Euro Zone.

${ }^{5}$ There are only three extreme observations, namely the Asian Crisis, "9.11" and the anniversary that fall in the panel sample period.
} 

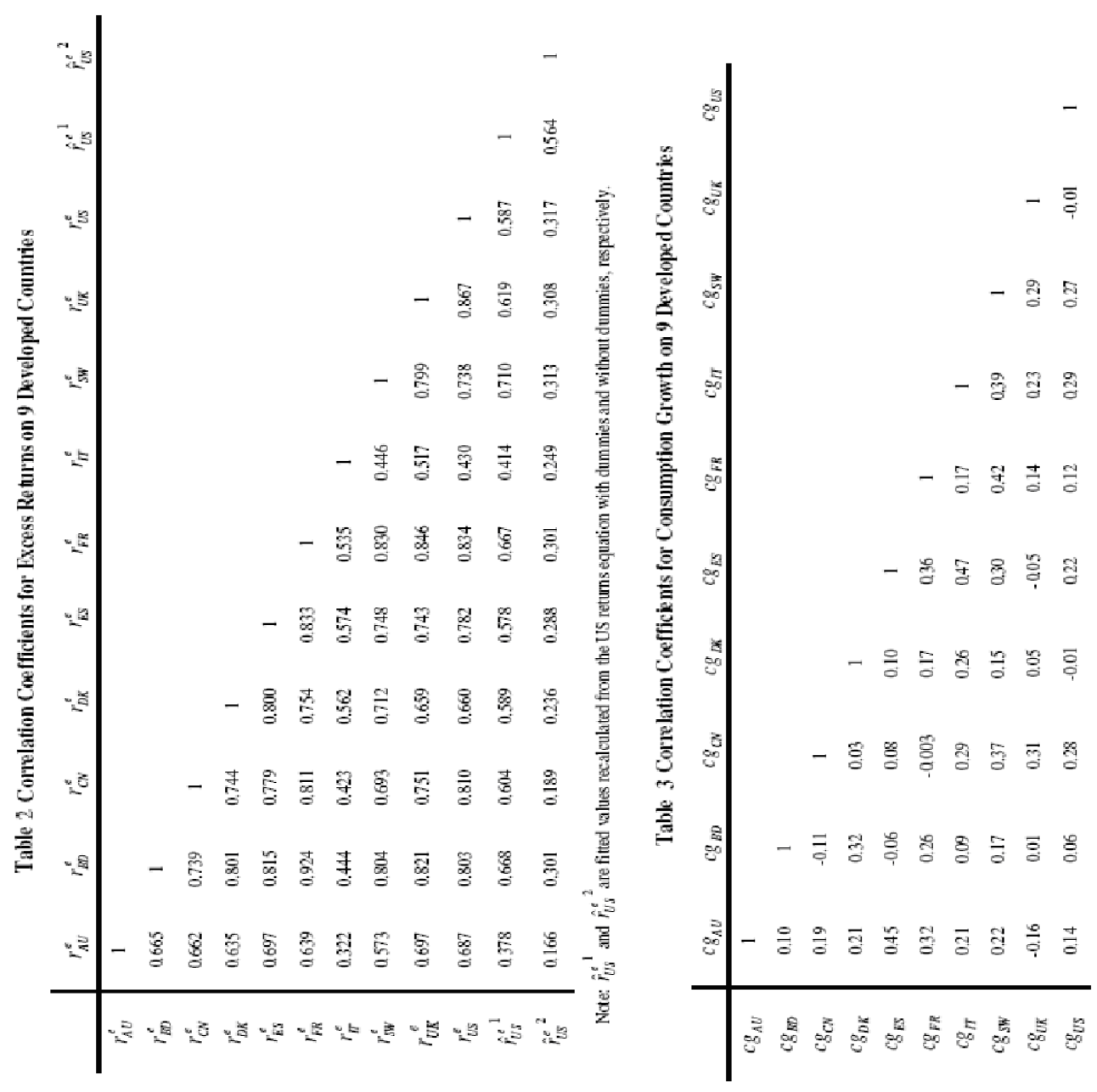
From Table 2, an obvious conclusion can be drawn that the Australian and Canadian stock markets are the two smallest markets that are still correlated with the US market even after correction for the effects of the extreme observations associated with the sample period (they take values of 0.17 and 0.19 respectively). An interesting example is the Canadian market. When the outliers are included, the correlation coefficients with the US stock market is very large, to the extent that one might imagine that the Canadian investor is not interested in their own market, rather, they prefer to participate in the US stock market. It is also worth noting from Table 3 that the growth in consumption across countries is not significantly correlated. The symbol $\hat{r}_{U S}^{e}$ will be used for simplicity instead of $\hat{r}_{U S}^{e}{ }^{2}$ for the remainder of this article.

Combining all the descriptive statistics associated with the panel data, it is apparent that the returns on different stock markets can be significantly different from each other, although their correlations are comparatively strong. However, consumption growth across countries is less inter-related, and this might indicate their lower variation relative to stock prices. All in all, it seems that the heterogeneity of national returns is worth investigating, particularly under the premise that consumer behaviour would appear to be heterogeneous.

\section{The Methodology}

\subsection{The Panel Model}

The heterogeneous linear panel regression model is based on the linearized model investigated by Hunter and $\mathrm{Wu}(2009)^{6}$ :

$$
r_{t}^{e}=-\log \alpha-\log \beta+\gamma_{1} c g_{t}+\gamma_{2} \hat{r}_{U S, t}^{e}+\mu_{t}
$$

In the above two-factor model, $\beta$ is the time discount factor; $r_{t}^{e}, c g_{t}$ and $\hat{r}_{U S, t}^{e}$ denote the excess returns and consumption growth in one specific country, and the predicted excess returns on the US stock market. Equation (1) can be estimated by 12-lagged-instruments either by IV or GMM, although the latter has been preferred in time series analysis of late.

Accordingly, the empirical two-way error component specification of a balanced panel data regression can be defined as:

$$
\begin{gathered}
r_{i, t}^{e}=c_{i}+(\log \beta)+\gamma_{i, 1} c g_{i, t}+\gamma_{i, 2} \hat{r}_{U S, t}^{e}+\mu_{i t} \\
i=1 \ldots I, t=1 \ldots T \\
\mu_{i t}=\alpha_{i}+\lambda_{t}+\epsilon_{i t}
\end{gathered}
$$

An assumption needs to made with respect to $\beta$, the time discount factor as it is not identified. Here it is assumed to be 0.99 . for $i=1 \ldots 9$ the country index representing the nine country codes (used by DataStream) for the major stock markets of developed countries other than the US. That is: Australia, Germany, Canada, Denmark, Spain, France, Italy, Switzerland and the United Kingdom, respectively. While $t=1 \ldots 51$ is a quarterly time index starting at 1992:Q2. In this panel data framework, the common constant $c_{i}$ is a scalar parameter

\footnotetext{
${ }^{6}$ Hunter and $\mathrm{Wu}(2009)$ suggest by comparison with the power utility function the degree of any non-linearity is small.
} 
and the parameters $\gamma_{i, 1}$ and $\gamma_{i, 2}$ are allowed to be heterogeneous. $\mu_{i t}$ defines an error term that may contain any of following effects: country-specific $\alpha_{i}$, period specific $\lambda_{t}$ and an idiosyncratic disturbance, $\epsilon_{i t}$ independently distributed over time and the cross-section with a mean of zero and a heterogeneous variance, $\sigma_{i}^{2}$

A virtue of panel data analysis is that it permits a simple specification for heterogeneity either at the country specific level via $\alpha_{i}$ or the period specific level via $\lambda_{t}$. Investors are different to one another, then consumer behaviour is likely to be heterogeneous (i.e., Constantinides and Duffie, 1996). Also, investors/consumers may be sensitive to trends and fashions suggesting that behaviour may fluctuate over time, and thus, heterogeneity can exist over time. Departing from this idea, it appears that aggregated heterogeneity can outperform investors/consumers heterogeneity in that it is more persistent, yet reduces the measurement errors in regressors, i.e. population. Consequently, the persistence of heterogeneity can be found in panel data with positive correlations, that can be induced either through a dynamic pattern or unobserved variables.

Conditional on data availability fixed effect errors are suitable for a small number of factors while a large sample is required for random effect errors. Therefore, it is likely that $\alpha_{i}$ and $\lambda_{t}$ should be treated as fixed effects and random effects respectively. The $\alpha_{i}$ are all zeros if treated as random effects, while too many period fixed effect $\lambda_{t}$ can easily lead to singularity of the estimated residual correlation matrices. Consequently, $\alpha_{i}$ can capture cross section heterogeneity, which means that it can show the net effect of any unobserved variables on the dependent variable (individual market returns). On the other hand, any latent period heterogeneity that varies over time can be captured by $\lambda_{t}{ }^{7}$

Econometric issues are particularly important in this two-stage regression because Hunter and Wu (2009) suggest that expected excess returns from the US stock market are likely to be measured with error, leading to biased estimates of these coefficients. Firstly, the Two Stage Least Square (2SLS) or Instrumental Variable (IV) estimator is required to eliminate the correlation between endogenous regressors and the disturbances. Secondly, Panel Corrected Standard Errors (PCSE), pioneered by Beck and Katz $(1995,1996)$ are employed to construct robust coefficient covariances for panel corrected residuals. ${ }^{8}$

Thirdly, although there is no obvious reason to believe that regressors are non-stationary such that a panel model has autocorrelated errors, it may suffer from heteroscedastic errors that can be either across individuals or over time periods, therefore, a Generalized Least Squares (GLS) approach is used to generate estimates of the robust coefficient covariances. Analogous to GLS in time series analysis, GLS applications for panel data analysis have four basic variance structures as weights that are conditional on the combinations of $i$ and $t$. That is cross-sectional heteroscedasticity, period heteroscedasticity, contemporaneous covariance (cross-section Seemingly Unrelated Regression Estimator (SURE)), period heteroscedasticity and serial correlation (time series SURE). For exam-

\footnotetext{
${ }^{7}$ Hausman specification tests imply under the null hypothesis that the random effects specifications are not significant.

${ }^{8} \mathrm{~A}$ key advantage of PCSE is that it takes into account the complexity of cross-sectional error processes while it does not require the data to be contemporaneously or serially uncorrelated, or panel homoscedastic. Thus, PCSE can be used when residuals are nonspherical. PCSE also has better small sample properties due to the block diagonal variance-covariance matrix.
} 
ple, the covariance structure of the cross section SURE allows for conditional correlation between contemporaneous residuals for cross section $i$ and $j$, but restricts residuals in different periods to be uncorrelated. ${ }^{9}$

Lastly, for robust covariance estimation for generated regression, the standard errors of disturbances in panel models should be corrected through crosssectional residuals that are recalculated by the actual values of the US excess returns, ${ }^{10}$ though robust standard errors are still asymptotically consistent in each stage. ${ }^{11}$

However, in a two step regression model, inference is calculated using

$$
\begin{aligned}
& V\left(\hat{\beta}_{\mathrm{F} 2 \mathrm{SGLS}}\right) \\
= & \frac{N}{N-K}\left(\sum X^{* \prime} Q P_{\tilde{Z}_{i}} Q X^{*}\right)^{-1}\left(\sum X^{* \prime} \hat{\Omega}_{I} X^{*}\right)\left(\sum X^{* \prime} Q P_{\tilde{Z}_{i}} Q X^{*}\right)^{-1} \\
& \stackrel{a}{\rightarrow} \frac{N}{N-K}\left(\sum X^{\prime} Q P_{\tilde{Z}_{i}} Q X\right)^{-1}\left(\sum X^{\prime} \hat{\Omega}_{I} X\right)\left(\sum X^{\prime} Q P_{\tilde{Z}_{i}} Q X\right)^{-1} .(3)
\end{aligned}
$$

in the second step these are only consistent with the equations regressed on the residuals of the actual variables, not those of generated ones. In other words, due to the incorrect residuals used for the variance matrix, standard errors are still biased compared with the results of models regressed directly on the actual variables. Therefore, the transformation matrix $\Psi=\sum X^{\prime} \hat{\Omega}_{I} X$ take the crosssectional PCSE as an example, needs to be recalculated by $\hat{\Omega}_{I}=\hat{\epsilon}^{\prime} \hat{\epsilon} / T \otimes I_{T}$ rather than by $\tilde{\Omega}_{I}=\tilde{\epsilon}^{\prime} \tilde{\epsilon} / T \otimes I_{T}$, where $\hat{\epsilon}$ is a vector of stacked residual series of $I$ cross-section specific regressions with the actual values of US excess returns, where $\otimes$ is the Kronecker Product (Dhrymes, 1984). The actual values of US excess returns $\hat{\epsilon}$ can be calculated using:

$$
\hat{\epsilon}_{i}=r_{i}^{e}-\hat{c}_{i}-\left[\begin{array}{ll}
\hat{\gamma}_{i, 1} & \hat{\gamma}_{i, 2}
\end{array}\right] \times\left[\begin{array}{c}
c g_{i, t} \\
r_{U S, t}^{e}
\end{array}\right]-\hat{\alpha}_{i}-\hat{\lambda}_{t} .
$$

By applying a procedure similar to the one used in Hunter and Wu (2009) it follows that:

$$
\tilde{\epsilon}_{i}=r_{i}^{e}-\hat{c}_{i}-\left[\begin{array}{ll}
\hat{\gamma}_{i, 1} & \hat{\gamma}_{i, 2}
\end{array}\right] \times\left[\begin{array}{c}
c g_{i, t} \\
\hat{r}_{U S, t}^{e}
\end{array}\right]-\hat{\alpha}_{i}-\hat{\lambda}_{t} .
$$

Where:

$$
\hat{\epsilon}_{i, t}=\tilde{\epsilon}_{i, t}+\hat{\gamma}_{i, 2}\left(\hat{r}_{U S, t}^{e}-r_{U S, t}^{e}\right) .
$$

Applying the recalculated $\hat{\epsilon}$ to the equation for

$$
\hat{\Omega}_{I}=\hat{\epsilon}^{\prime} \hat{\epsilon} / T \otimes I_{T}
$$

gives rise to the bias corrected coefficient variance-covariance matrix:

\footnotetext{
${ }^{9}$ This weighting transformation is named cross section SUR since it only considers the contemporaneous correlations, that resemble the common SUR definition.

${ }^{10}$ The literature on whether it is still necessary in generated regression to correct standard error biases induced by generated variables is inconclusive (i.e. see Liang and Zeger, 1986; Hu and Lachin, 2001; Souleles, 2004).

${ }^{11}$ See Hunter and $\mathrm{Wu}(2009)$. The same result is concluded using Lemma 12.1 in Woodridge (2002).
} 


$$
\begin{aligned}
& V_{B C}\left(\hat{\beta}_{F 2 S G L S}\right) \\
= & \frac{N}{N-K}\left(X^{\prime} Q P_{\tilde{Z}_{i}} Q X\right)^{-1}\left(X^{\prime} \hat{\epsilon}^{\prime} \hat{\epsilon} / T \otimes I_{T} X\right)\left(X^{\prime} Q P_{\tilde{Z}_{i}} Q X\right)^{-1} .
\end{aligned}
$$

Then the bias corrected standard errors of coefficients can be obtained using:

$$
S E_{B C}\left(\hat{\beta}_{F 2 S G L S}\right)=\operatorname{diag} V_{B C}\left(\hat{\beta}_{F 2 S G L S}\right) .
$$

\section{Empirical Results}

In a panel setting, the linear form of the C-CAPM pooles the excess returns for nine individual countries. In the case of the extended two factor models we regress the pooled variable on country specific consumption growth and expected US excess returns. As far as the instrument set is concerned, consumption growth is implicitly explained by 4 lags of country-specific excess returns and rates of consumption growth; expected US excess returns up to 2 lags are included as a two step regressor that instruments itself; 2 lagged actual US excess returns are also employed as additional instruments in order to capture potential heteroscedasticity in panel residuals. As for the econometric methodology, the Feasible Generalized Two stage Least Squares (FG2SLS) is deployed.

The dynamic tests chosen here are for autocorrelation, heteroscedasticity and the validity of instruments. The autocorrelation test is the first-order Breusch and Godfrey LM test that operates across all vectors of cross-sectional residuals, while the heteroscedasticity test is an augmented Breusch-Pagan test proposed by Bickel that can take account of both within and between country heteroscedasticity. The validity of the instrumental variables is tested using Sargan's test of over-identifying restrictions. This is a J-statistic that evaluates whether instruments and estimated residuals are orthogonal given the estimated parameters (Arellano and Bond, 1991):

$$
J=\hat{\epsilon}^{\prime} Z\left(\sum Z_{i}^{\prime} \hat{\epsilon}_{i} \hat{\epsilon}_{i}^{\prime} Z_{i}\right)^{-1} Z^{\prime} \hat{\epsilon} \sim \chi_{p-k}^{2}(\alpha) .
$$

The existence of either autocorrelation or heteroscedasticity in the residuals can lead in the dynamic panel context to biased and inconsistent estimates, and thus models that suffer from these problems are often misspecified. The Sargan test is sensitive to any form of misspecification, but for models that are otherwise correctly formulated a significant J-statistic suggests that the instruments are invalid.

\subsection{Pooled Panel Models with Common Coefficients}

The panel model with common coefficients assumes cross section consumption growth has the same coefficient across the panel, and then such a model can be estimated by FG2SLS with cross section Panel Corrected Standard Errors (PCSE) as robust covariances. Further consideration of fixed and random effects yields four different specifications, the results of which are reported in Table 4 . The second column of Table 4 depicts the outcome of a panel model without any error component correction. In this case, the model simply stacks all the 
data over the cross sections, and thus a single variable is regressed with $T \times I$ observations. These results are presented for the purpose of comparison as one may argue that both the

$$
\operatorname{Cov}\left(\hat{r}_{U S, t}^{e}, \mu_{i t}\right) \neq 0
$$

and

$$
\operatorname{Cov}\left(c g_{i, t}, \mu_{i t}\right) \neq 0
$$

in the presence of inter-country unobserved heterogeneity. Hence, the next three columns of Table 4 give the results of panel models with cross section fixed effects, period random effects and both kinds of effects, respectively.

Comparing the three coefficient sets, from a theoretical perspective we prefer the results associated with the model with cross section fixed effects, since all three coefficients are significant at the $5 \%$ level after correcting for biases in the standard errors. ${ }^{12}$ Further, the model also seems well specified on the basis of the dynamic tests for autocorrelation and heteroscedasticity that cannot reject the null, and the validity of the instrument set also cannot be rejected at the $5 \%$ level.

The introduction of fixed effects dramatically increases the size of the risk aversion parameter to $4.285,{ }^{13}$ which is consistent with economic theory. ${ }^{14}$ The fixed effect is a country specific intercept that can be interpreted as capturing fixed differences in country-level average excess returns over the sample period. These fixed effects thus can help control for any time constant omitted variable bias that my influence consumers' decision on expenditure. In this sense, a panel model with country fixed effects can more clearly reflect the risk aversion of consumers across different countries than asset pricing models without the fixed effects, because it captures a component of country specific risk that then does not accentuate, intracountry differences in the pooled estimates of the rate of risk aversion.

The panel model with fixed effects suggests that long run stock market behaviour across countries is only different in a fixed way. Although the inclusion of a constant $(-0.382)$ can also capture a long run effect, it cannot remove all of such effects if the long run averages are heterogeneous as would appear to be the case here. For example, the UK and the Australian stock markets have negative long run average returns (-.018 and -.017, respectively). On the other hand, the average returns of Switzerland and Italy in the long run are .017

\footnotetext{
${ }^{12}$ The bias correction for the coefficient variance-covariance matrix based upon recalculated residuals suggests the standard errors are adjusted downward in line with the results in Hunter and $\mathrm{Wu}(2009)$.

${ }^{13}$ Assuming that we give preference to the models that correct for heterogeneity, then it should be noted that the model with cross section fixed effects estimated until the end of 2010 gives rise to coefficiencts that although lower are not significantly different from the results in table 4. For the model with cross section fixed effects, the coefficient on predicted US excess returns being 0.849 as compared with .869 and the coefficient on pooled consumption growth 2.624 when compared with 4.285 .

${ }^{14}$ Mehra and Prescott (1985) quote several micro-econometric estimates that bound risk aversion by 3, and Mehra and Prescott(1988) later clearly chose an upper bound as large as ten merely as a rhetorical flourish. Therefore, it would appear that the restriction that the risk aversion coefficient should be less than ten is more controversial (Kocherlakota, 1996), and an individual with a coefficient of relative risk aversion above ten would be willing to pay unrealistically large amounts to avoid bets (Mankiw and Zeldes, 1991).
} 
and.012 respectively. The rest of the countries are less variable with long run average returns in the range $[-.007, .009] .{ }^{15}$

Although the panel C-CAPM model with only common regressors is simple to apply, it cannot give insight into any unobserved heterogeneity caused by simultaneous correlations, omitted variables, or measurement errors. Given that the fixed effect heterogeneity of country long run averages in the panel C-CAPM does vary it is natural to wonder whether country specific rates of risk aversion themselves are heterogeneous. Indeed, analysis of consumption heterogeneity is necessary and obvious since the effect of consumption on returns can be quite complicated, casting doubt on the static linear panel C-CAPM where consumption growth is a common regressor. The idea that consumption behaviour may differ in a non-constant and non-random way would suggest that it ought to be treated differently for each country in the panel. ${ }^{16}$

\subsection{Pooled Panel Models with Country Specific Consump- tion Growth Effects}

Table 5 presents a selection of panel models with country specific consumption growth coefficients estimated by 2SGLS. For comparison, the same sets of weighting and covariance matrices are applied as were in Table 4. As far as the dynamic tests are concerned, there is not any first-order autocorrelation and Sargan's test of instrument validity/over-identifying restrictions can also be satisfied. However, rejection of homoscedasticity at the $10 \%$ significance level in all the four specifications in Table 5 may suggest that the residuals are heteroscedastic. Further inspection of the residuals by country suggests that there is not any heteroscedasticity up to fourth orders within each individual series, but cross-sectional heteroscedasticity across the panel. This might have been expected as Beck and Katz (1995) suggest that panel data tends to suffer from non-spherical behaviour in the disturbances caused by the cross-sectional dimension of the problem. ${ }^{17}$ If the non-spherical behaviour of the disturbances arises purely by virtue of non-time invariant heteroscedasticity, then the usual heteroscedasticity-robust standard errors and test statistics from the pooled least squares regression can be used (Wooldridge, 2002, pp.178) and so to this end the PCSE weights are used.

One problem that arises from the application of corrected standard errors subject to the generated regressor problem follows from the application of Hausman tests to compare the parameters of different fixed and random effects models. As the corrected standard errors may be larger or smaller than the conventional ones, their differential can be negative. When the differential is positive and the variance estimate consistent, then we consider a sequence of Hausman tests coefficient by coefficient. If such differences are deemed significant at the $1 \%$ level for more than half the parameters we give preference to the model that has both random and fixed effects. With the exception of cross

\footnotetext{
${ }^{15}$ When the sample is extended these differences are also reduced with the UK falling to -.00759 and the largest effects being associated with Australia at -.0115 and Germany .0102 .

${ }^{16}$ Here, we feel the panel evidence is a useful adjunct to the UK study, suggesting that multifactor models driven by US excess returns are supported in the main. Country specific models are beyond the scope of this study and given the data limits associated with Germany the analysis would not be viable.

${ }^{17}$ Panel Heteroscedasticity means that the variance of the error term within a cluster is constant, but it varies across clusters.
} 
sectional heteroscedasticity, the final specification is expected to satisfy all the tests of specification: no serial correlation, valid instruments and no correlation in squared country specific auto-correlations. It follows from the results in Table 5 and the results of the Hausman Test for the period random effect comparisons in Table 6 that our preferred specification is the model with both country specific fixed effects and period random effects. As can be observed from the Hausman tests a sizeable number of the coefficients differ from the model without random effects.

The model with both country specific fixed effects and period random effects has the only negative cross sectional consumption growth coefficient, which is not significant. Also, Italy has the largest, positive consumption coefficient of 12.71 , which is obviously different from those of other countries. It would appear that the lowest correlation (.43) between the Italian and the US stock markets can explain this high risk aversion rate. The low correlation may be due to the particular nature of corporate structure in Italy. Also in the 1990s, the personal consumption expenditure of Italy would have been more likely to reflect national economic health and this was reflected in the response of the Italian stock market. In fact, except for Spain and Italy, the model with fixed and random effects has a common excess return response for all countries and different consumption effects ranging between [1.53,5.32], which is again well in line with economic theory.

Both Table 4 and Table 5 reveal the significant and consistent influence (.869 and 1.043, respectively) of the US stock market over the stock markets of other countries, which is not surprising due to the dependence of non-US markets on the US stock market in some form, i.e. stock prices, returns and/or volatilities. In practice, as interest rates can be used for evaluating riskless assets, financial practitioners may also look for some criteria for assessing performance of their risky investments, and due to the fact that the US stock market is the most highly capitalized, it has become a performance benchmark. First, more and more international companies are now traded in New York, accelerating the fusion of financial markets, and thus making the US market a key component for portfolio and risk diversification. Also, there are more companies, particularly European companies that are running large businesses in North America, so the US consumer's sentiments will inevitably influence their revenues. Third, different industries are gathered to and may play equivalent roles in the US, while some national stock markets are highly sensitive to specific industries, i.e. car manufacturing in Germany. In the era of a globalized economy, shocks affecting industry may further accelerate stock market integration. All in all, at least when modelling risk using consumption, this research indicates how important a role the US stock market has in the process of valuing risk across the globe and in the pricing of assets way beyond it's borders.

\section{Conclusion}

This article focuses on a linearized form of the Consumption-based CAPM in a pooled cross section panel model with two-way error components. Specifically, we assert that each country may have its own fixed effects across countries and random effects appear over time. The panel model is designed to extend the time series framework of Hunter and Wu (2009) that explains UK excess returns 
by UK consumption growth on US predicted excess returns. The panel model covers nine major developed stock markets with quarterly data over the period 1991:1-2004:4. The empirical findings of the panel models based on a range of specifications that capture fixed and random effects all indicate that there is significant heterogeneity and heteroscedasticity but no apparent autocorrelation across the nine countries. In particular, unobserved heterogeneity described by fixed effects offsets the effect of the US stock market. Although the average risk aversion coefficient is 4.285 across the sample, the cross-sectional impact of home consumption growth varies dramatically over the countries observed here, unobserved heterogeneity of which can also be addressed by random effects given the Hausman test statistic and other dynamic test results.

It can be observed from this analysis that important aspects of the world banking crisis in 2007-8 are reflected in the response to financial asset movements across the globe. Economies not sensitive to the direct impact of the failure of liquidity that arose from the breakdown of the credit default swap (CDS) market in August 2007 and the resulting bank failure that culminated in the failure of the US Government to act on the collapse of a wholesale bank Lehman Brothers (Milne, 2009).

The multifactor model presented here and estimated before the crisis implies that stock returns will be squeezed by the failure of liquidity and resultant increase in interbank rates in 2007. Something not acted on for more than twelve months in the UK by the Bank of England. It is evident from the analysis in Gregoriou et al (2009) that the normal response of the US Federal Reserve Bank to Stock Market crises was to introduce liquidity into the market via monetary expansions. This occurred in the UK and the US following the stock market crash in 1987, and in the US in response to the Asian Crisis and 9/11. It seems that the monetary authorities in the US and the UK was initially limited in relation to the Banking crisis in 2007-8. The initial position of the Governor of the Bank of England being that the crisis related to poor bank practice and that led to a period of more than 12 months of inaction in terms of interest rates and expanding liquidity. It would appear from the analysis conducted here that a rapid global response would have greatly ameliorated the later and developing impact the financial crisis that came to a head in September 2008.

The next factor whose effect is estimated by the model relates to the direct financial consequences of the failure of Lehman brothers. The failure of this wholesale bank was a catalyst for a global crisis in the financial markets that became embedded in the value of stock indices across the world. As can be observed from the model, asset values even in countries such as Spain and Italy without a primary connection to the underlying drivers of the crisis are impacted by the collapse of US asset values. This arises even though their banks were not involved in significant holdings in the CDS and Mortgage Backed Securities (MBS) markets (Milne, 2009). Model shows that US stock prices have an effect close to unity on UK excess returns and this of other major European Economies plus Australia and Canada.

A secondary feature of the crisis relates to corporate failure and it can be shown for the UK (Hunter and Isachenkova, 2006) and for other economies (Hunter and Isachenkova, 2001), that a key aspect of corporate failure is liquidity. In terms of macro variables, high nominal interest rates and real exchange rates in the case of the UK are a key failure predictor more than one year in advance. Hence, the incapacity of monetary authorities and the Monetary 
Policy Committee of the Bank of England to focus what on was happening in the financial markets and become fixated on inflation was to have severe consequences for corporate failure once the crises started to bite. The collapse in asset values induces increased problems with debt that are invidiously linked with the Basel II and the capacity of corporations to find liquidity in an already difficult market when debt to equity ratios are moving in the wrong direction (Hunter and Isachenkova, 2006).

This feeds into the final factor in the pricing of the assets, the fundamental relationship between stock performance and growth in the economy as captured by the consumption term in the multifactor model. This is further associated with corporate failures in the UK and Russia (Hunter and Isachenkova, 2001). The likely consequence of a failure of growth is to reduce asset values and this is further compounded by falling corporate sales turnover leading firms to fail.

Hence, the local and global return, nexus controlled for interest rates and growth, captured in the model considered here, explains key aspects of pricing the stock indices of the economies of the Australia, Canada, Denmark, France, Germany, Italy, Spain, Switzerland and the UK. The model also shows how the volatile nature of asset prices is embedded in the global market place as captured by US excess returns and this component of risk is required to deliver more appropriate rates of risk aversion and the significant impact of consumption growth on asset prices. The underlying volatility feed through is captured by the behaviour of global stock prices as captured by US excess returns.

\section{References}

Arellano, M. and Bond, S. (1991) Some tests of specification for panel data: Montecarlo evidence and an application to employment equations Review of Economic Studies, 58, 277-297

Arellano, M (2002) Sargan's Instrumental Variables Estimation and the Generalized Method of Moments, Journal of Business \& Economic Statistics, 20, 450-459.

Balduzzi, P. and Yao, T. (2007) Testing heterogeneous-agent models: an alternative aggregation approach. Journal of Monetary Economics, 54, 369-412.

Beck, N and Katz, J.N. (1995) What to do (not to do) with time-series cross-section data, American Political Science Review 89, 634-647.

Beck, N and Katz, J.N. (1996) Nuisance v. substance: specifying and estimating timeseries-cross-section data, Political Analysis 6, 1-36.

Campbell, J. Y. and Cochrane,J.H. (2000) Explaining the poor performance of consumption based asset pricing models, Journal of Finance 55, 2863-2878.

Cogley, T (2002) Idiosyncratic risk and the equity premium: evidence from the consumer expenditure survey, Journal of Monetary Economics 49, 309-334.

Constantinides, G.M. and Duffie, D. (1996) Asset pricing with heterogeneous consumers, Journal of Political Economy, 104,219-240.

Dhrymes, P. J. (1984) Mathematics for Econometrics, New York: Springer-Verlag. Gregoriou, A., Hunter, J., Wu, F., (2009). An empirical investigation of the relationship between the real economy and sock returns for the United States. Journal of Policy Modeling 31, 133-143.

Hamao, Y., Masulis, R. W. and Ng, V. (1990) Correlations in price changes and volatility across international stock markets, Review of Financial Studies, 3, 281-307.

Hsiao, C. (2003) Analysis of Panel Data, Vol. 34 of Econometric Society Monographs. 
Cambridge University Press, Cambridge, 2nd edition.

Hsiao, C. (2007). Panel data analysis - advantages and challenges. Test, 16, 1-22

$\mathrm{Hu}, \mathrm{M}$ and Lachin, J. M. (2001) Application of robust estimating equations to the analysis of quantitative longitudinal data, Statistics in Medicine, 20, 3411-3428.

Hunter, J and N Isachenkova. (2001), Failure Risk: A Comparative Study of UK and Russian Firms, Journal of Policy Modelling, 23/5, 511-521

Hunter, J and N Isachenkova. (2006), Aggregate Economy Risk and Company Failure: An Examination of UK Quoted Firms in the Early 1990s, Journal of Policy Modeling, 28, 911-919.

Hunter, J and Wu, F. (2009), A Multifactor Consumption based Asset Pricing Model of the UK Stock Market: The US Stock Market as a Wealth Reference, paper presented at the EEFS conference in Warsaw, 2009 and the Infiniti conference in Dublin, 2010 and Brunel University Discussion paper, 09-01.

Jacobs, K. (1999) Incomplete markets and security prices, do asset-pricing puzzles result from aggregation problems? Journal of Finance 54,123-163.

Jacobs, K. and Wang, K.Q. (2004) Idiosyncratic consumption risk and the cross-section of asset returns, Journal of Finance, 59, 2211-2252.

Kocherlakota, N. (1996) The equity premium, it's still a puzzle. Journal of Economic Literature 34, 42-71.

Liang, K. Y. and Zeger, S. L. (1986) Longitudinal data analysis using generalized linear models. Biometrika, 73, 13-22

Lucas R. Jr. (1978) Asset prices in an exchange economy, Econometrica 46,1429-1445. Lund, J. and Engsted, T. (1996). GMM and present value tests of the C-CAPM: evidence from the Danish, German, Swedish and UK stock markets, Journal of International Money and Finance 15, 497-521.

Mehra, R. and Prescott, E.C. (1985) The Equity Premium, A Puzzle. Journal of Monetary Economics 15, 145-61.

Milne, A, (2009), The Fall of the House of Credit: What Went Wrong in Banking and What can be Done to Repair the Damage?, Cambridge University Press, Cambridge. Miller, E. (1977) Risk uncertainty and divergence of opinion. Journal of Finance 32, $1151-1168$.

Opoku, N.P. (2007) Optimum Portfolio Allocation Decisions in a Dynamic Setting using Alternative Measures of Risk, Ph.D. thesis, Brunel University.

Semenov, A. (2003) High-Order Consumption Moments and Asset Pricing, York University WP-2003-12-1.

Wei, K. C.J (1988) An Asset-Pricing Theory Unifying CAPM and APT, Journal. of Finance, 43, 881-892. 5.

Weil, P. (1989) The equity premium puzzle and the risk-free rate puzzle. Journal of Monetary Economics 24 (3), 401-21.

Wooldridge, J. M. (2002) Econometric Analysis of Cross Section and Panel Data, MIT Press. 
Table 4 Pooled Panel Models with Common Coefficients

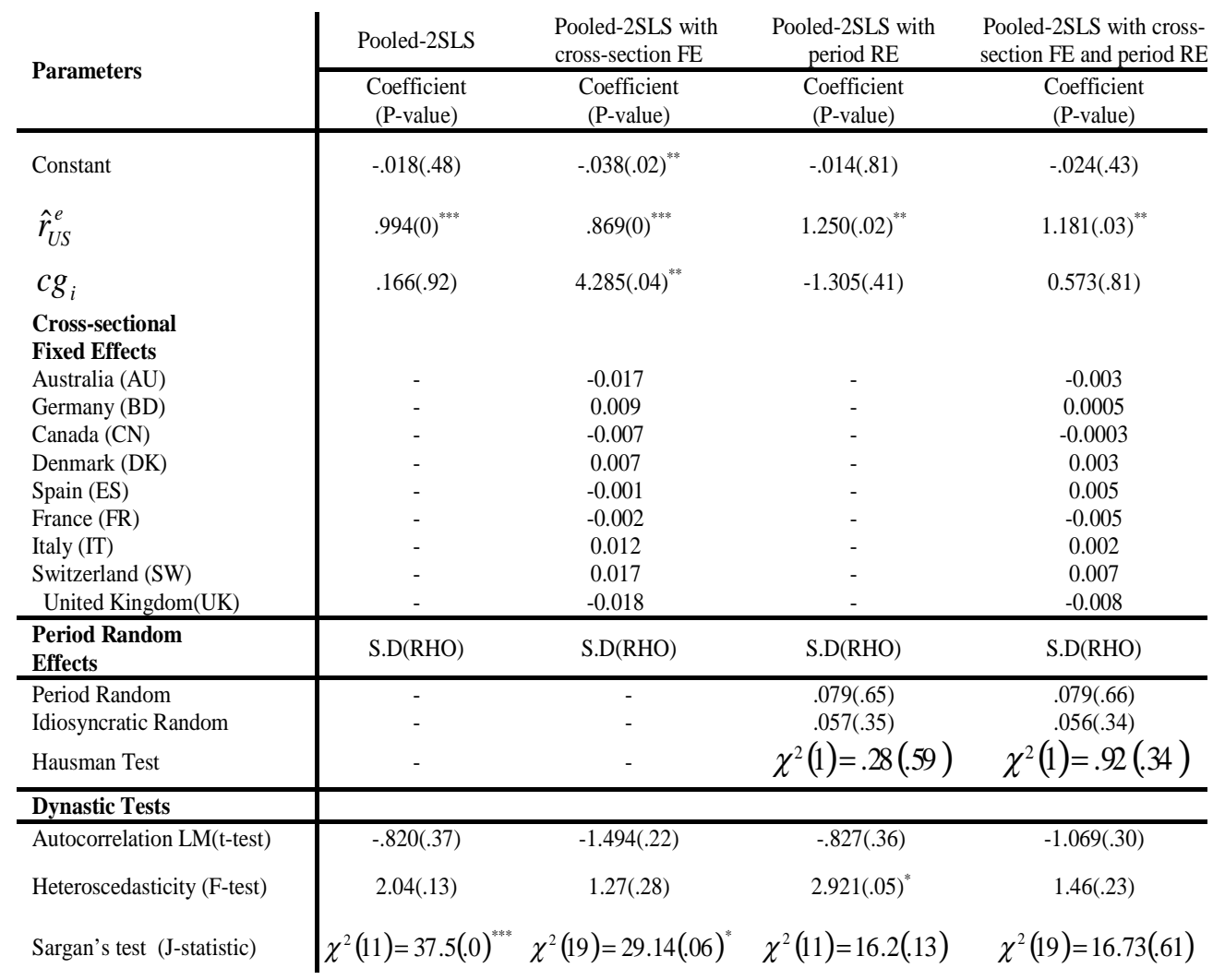

Notes: 1 The subjective discount factor is restricted to assume the value of $\hat{a}$ $=0.99 .2 \mathrm{p}$-values are given in parenthesis and ${ }^{* * *}{ }^{* *}$ and ${ }^{*}$ : Significant levels of the $1 \%, 5 \%$ and $10 \%$, respectively. 3. Pooled-2SLS and Pooled-2SLS with cross-section FE is estimated by 2SGLS with cross section weights and corrected for PCSE weights; Pooled-2SLS with period RE and Pooled-2SLS with cross-section FE and period RE are estimated by 2SGLS corrected for PCSE weights. 4.The instruments chosen are expected US excess returns, current and lags one and two, 2 lags in actual US excess returns, 4 lags of cross-country excess returns and lagged cross-country real consumption growth rates that can be either common or cross-country specific. 5 Common instrument sets are country-specific excess returns, the expected returns (estimated without dummies) and the individual rates of consumption growth, up to 4 lags. 6 . Autocorrelation test is based on first-order Breusch and Godfrey LM test across all vectors of cross-sectional residuals, that is, $L M=\sqrt{N T^{2} / T-1} \times r \sim \chi^{2}(1)$ where $r=\sum_{i} \sum_{t=2} \hat{\epsilon}_{i t} \hat{\epsilon}_{i, t-1} / \sum_{i} \sum_{t=2} \hat{\epsilon}_{i t}^{2}$. 7. The heteroscedasticity test is Bickel's version of the Breusch-Pagan test for the joint-significance of the two power predictions in the pooled equation: $\hat{\epsilon}_{i t}^{2}=\gamma_{0}+\gamma_{1} \hat{y}_{i t}+\gamma_{2} \hat{y}_{i t}^{2}+\nu_{i t} 8$. The validity test for instrument variables is tested by the Sargan Test. 9 The variance-covariance matrix of the estimated coefficients is corrected using equations (7) and (8). 
Table 5 Pooled Panel Models with Consumption Growth as a Cross Section Specific Parameter

\begin{tabular}{|c|c|c|c|c|}
\hline \multirow{2}{*}{ Parameters } & Pooled-2SLS & $\begin{array}{l}\text { Pooled-2SLS with } \\
\text { cross-section FE }\end{array}$ & $\begin{array}{l}\text { Pooled-2SLS with } \\
\text { period RE }\end{array}$ & $\begin{array}{l}\text { Pooled-2SLS with cross- } \\
\text { section FE and period RE }\end{array}$ \\
\hline & $\begin{array}{c}\text { Coefficient } \\
\text { (P-value) }\end{array}$ & $\begin{array}{l}\text { Coefficient } \\
\text { (P-value) }\end{array}$ & $\begin{array}{c}\text { Coefficient } \\
\text { (P-value) }\end{array}$ & $\begin{array}{c}\text { Coefficient } \\
\text { (P-value) }\end{array}$ \\
\hline Constant & $-0.027(0)^{3 * * * *}$ & $-0.040(0)^{* * * * *}$ & $-0.026(0)^{* * * * \%}$ & $-0.035(0)^{* * * * * 6}$ \\
\hline$\hat{r}_{U S}^{e}$ & $0.864(0)^{\text {**** }}$ & $0.910(0)^{* * *}$ & $1.088(0)^{\text {**** }}$ & $1.043(0)^{\text {**** }}$ \\
\hline$c g$-Australia (AU) & $1.109(.42)$ & $3.374(0)^{* * *}$ & $0.723(0)^{* * * *}$ & $3.618(0)^{* * * *}$ \\
\hline$c g$-Germany (BD) & $6.739(.10)^{*}$ & $4.013(0)^{* * * *}$ & $3.706(0)^{* * * *}$ & $2.436(0)^{* * * *}$ \\
\hline$c g$-Canada $(\mathrm{CN})$ & $2.302(.18)$ & $8.685(0)^{* * * *}$ & $1.362(0)^{* * * *}$ & $5.319(0)^{\text {***** }}$ \\
\hline$c g$-Denmark (DK) & $0.453(.49)$ & $-6.181(0)^{* * * *}$ & $-0.828(0)^{* * * *}$ & $1.530(0)^{\text {**** }}$ \\
\hline$c g$-Spain (ES) & $1.428(.51)$ & $0.602(.25)$ & $0.938(0)^{\text {**** }}$ & $-0.147(.17)$ \\
\hline$c g$-France (FR) & $1.210(.72)$ & $-4.254(0)^{* * * *}$ & $1.378(0)^{* * * *}$ & $2.976(0)^{\text {**** }}$ \\
\hline$c g$-Italy (IT) & $8.793(0)^{\text {**** }}$ & $9.871(0)^{* * *}$ & $9.205(0)^{* * * *}$ & $12.71(0)^{\text {**** }}$ \\
\hline$c g$-Switzerland (SW) & $8.833(.10)^{*}$ & $12.10(0)^{* * *}$ & $3.175(0)^{* * * *}$ & $2.836(0)^{* * * *}$ \\
\hline $\begin{array}{l}c g \text {-United } \\
\text { Kingdom(UK) }\end{array}$ & $0.679(.69)$ & $11.85(0)^{* * * *}$ & $-0.431(0)^{* * * *}$ & $1.948(0)^{* * * *}$ \\
\hline \multicolumn{5}{|l|}{$\begin{array}{l}\text { Kingdom(UK) } \\
\text { Cross-sectional } \\
\text { Fixed Effects }\end{array}$} \\
\hline Australia (AU) & - & -0.007 & - & -0.017 \\
\hline Germany (BD) & - & 0.011 & - & 0.009 \\
\hline Canada $(\mathrm{CN})$ & - & -0.039 & - & -0.021 \\
\hline Denmark (DK) & - & 0.056 & - & 0.014 \\
\hline Spain (ES) & - & 0.027 & - & 0.025 \\
\hline France (FR) & - & 0.040 & - & -0.002 \\
\hline Italy (IT) & - & -0.003 & - & -0.018 \\
\hline Switzerland (SW) & - & -0.005 & - & 0.015 \\
\hline United Kingdom (UK) & - & -0.080 & - & -0.005 \\
\hline $\begin{array}{l}\text { Period Random } \\
\text { Effects }\end{array}$ & S.D(RHO) & S.D(RHO) & S.D(RHO) & S.D(RHO) \\
\hline $\begin{array}{l}\text { Period Random } \\
\text { Idiosyncratic Random }\end{array}$ & $\begin{array}{l}- \\
-\end{array}$ & $\begin{array}{l}- \\
-\end{array}$ & $\begin{array}{l}.084(.65) \\
.061(.35)\end{array}$ & $\begin{array}{l}.084(.65) \\
.061(.35)\end{array}$ \\
\hline Hausman Test ${ }^{\dagger \dagger}$ & - & - & & \\
\hline \multicolumn{5}{|l|}{ Dynastic Tests } \\
\hline Autocorrelation-LM (t-test) & $-1.013(.31)$ & $-1.300(.25)$ & $-.956(.33)$ & $-1.214(.27)$ \\
\hline Heteroscedasticity (F-test) & $3.24(.04)^{* * *}$ & $2.68(.07)^{*}$ & $4.85(.01)^{* *}$ & $11.3(0)^{* * * *}$ \\
\hline Sargan's test (J-statistic) & $\chi^{2}(35)=51.28(.04)^{* *}$ & $\chi^{2}(43)=45.89(.35)$ & $\chi^{2}(35)=21.29(.97)$ & $\chi^{2}(43)=26.05(.98)$ \\
\hline
\end{tabular}

Note: see Table 4 . The variance-covariance matrix of the estimated coefficients is corrected using equations (7) and (8). Due to robust standard errors that are also corrected for the generated regressor, problem, the Hausman test reports some negative variance differences $(\operatorname{var}(\mathrm{FE})$ - $\operatorname{var}(\mathrm{RE}))$ and thus cannot correctly calculate Chi squared statistic. Therefore, we use a t-statistic to test a single consumption growth parameter each time, ignoring the other parameters.(see Table 6) 
Table 6 Period Random Effect Comparisons - Hausman Test

\begin{tabular}{l|cccccc}
\multirow{2}{*}{ Panel Models } & \multicolumn{3}{|c}{ Pooled-2SLS with period RE } & \multicolumn{3}{c}{ Pooled-2SLS with cross-section FE and } \\
& \multicolumn{1}{c|}{ period RE } \\
\cline { 2 - 7 } & (FE-RE) & Var(FE)-Var(RE) & P-Value & (FE-RE) & Var(FE)-Var(RE) & P-Value \\
\hline$c g$-Australia (AU) & -0.022 & 0.000592 & 0.37 & -0.739 & 0.037178 & 0 \\
$c g$-Germany (BD) & -0.210 & -0.01524 & NA & -0.139 & -0.01075 & NA \\
$c g$-Canada (CN) & -0.037 & 0.000358 & 0.05 & -0.593 & 0.014019 & 0 \\
$c g$-Denmark (DK) & 0.157 & -0.01127 & NA & 0.728 & -0.01416 & NA \\
$c g$-Spain (ES) & -0.033 & -0.00116 & NA & -0.268 & -0.00044 & NA \\
$c g$-France (FR) & -0.038 & -0.0012 & NA & -0.198 & 0.002535 & 0 \\
$c g$-Italy (IT) & 0.036 & -0.01198 & NA & 0.112 & 0.002228 & .02 \\
$c g$-Switzerland (SW) & -0.209 & -0.002 & NA & -0.550 & -0.01782 & NA \\
$c g$-United Kingdom(UK) & -0.032 & 0.000333 & 0.08 & -0.984 & 0.041274 & 0
\end{tabular}

